Published in final edited form as:

Midwifery. 2013 June ; 29(6): 690-697. doi:10.1016/j.midw.2012.06.013.

\title{
IN A HARD SPOT: PROVIDING GROUP PRENATAL CARE IN TWO URBAN CLINICS
}

\author{
Gina Novick, CNM, PhD [Assistant Professor], \\ Yale School of Nursing
}

Lois S. Sadler, PhD, PNP-BC, FAAN,

Professor at the Yale School of Nursing and the Yale Child Study Center, and Assistant Dean for Academic Affairs at the Yale School of Nursing

Kathleen A. Knafl, PhD, FAAN,

Frances Hill Fox Distinguished Professor and Associate Dean for Research at the University of North Carolina at Chapel Hill

Nora E. Groce, PhD, and

Leonard Cheshire Chair and Director of the Leonard Cheshire Centre for Disability and Inclusive Development at University College London

Holly Powell Kennedy, PhD, CNM, FACNM, FAAN

Helen Varney Professor of Midwifery at the Yale School of Nursing and President of the American College of Nurse-Midwives

\section{Introduction}

Group prenatal care (GPNC) is an innovative approach to providing prenatal care that integrates prenatal physical examinations, health education, and peer support.

CenteringPregnancy (Centering), the predominant model of GPNC, has been implemented in over 300 sites in the United States since 1993 (S.S. Rising, CNM, written communication, 2009), and has been introduced in Canada, the UK, and Australia (Teate et al., 2009, Gaudion et al., 2011, Gaudion et al., 2011). Centering appears to produce pregnancy outcomes and experiences comparable or superior to individual care (Ickovics et al., 2007, Kennedy et al., 2009, Klima, 2009, Lu et al., 2010, Novick et al., 2011, Picklesimer et al., 2012). Centering provides substantially greater contact time with pregnant women than individual prenatal care, yet requires a minimal increase in provider time (Tanner-Smith et al., 2012). This multifaceted program is attractive to clinicians seeking to provide prenatal care that addresses pregnant women's emotional, social, and behavioral concerns (Rising et al., 2004, Klima, 2009, Tanner-Smith et al., 2012) and may be particularly beneficial for

\footnotetext{
(C) 2012 Elsevier Ltd. All rights reserved.

Addresses:

Gina Novick, Yale University School of Nursing, 100 Church St. South, PO Box 9740, New Haven, CT 06536-0740, USA, gina.novick@yale.edu, Cell phone: 203 494-1303, Fax: 203 784-6455

Lois Sadler, Yale University School of Nursing, 100 Church St. South, PO Box 9740, New Haven, CT 06536-0740, USA

Kathleen A. Knafl, University of North Carolina at Chapel Hill, School of Nursing Carrington Hall, CV \#7460, Chapel Hill, NC $27599-7460$

Nora E. Groce, University College, London, 1-10 Torrington Place, London, WC1\# 6BY

Holly Powell Kennedy, Yale University School of Nursing, 100 Church St. South, PO Box 9740, New Haven, CT 06536-0740, USA

Publisher's Disclaimer: This is a PDF file of an unedited manuscript that has been accepted for publication. As a service to our customers we are providing this early version of the manuscript. The manuscript will undergo copyediting, typesetting, and review of the resulting proof before it is published in its final citable form. Please note that during the production process errors may be discovered which could affect the content, and all legal disclaimers that apply to the journal pertain.
} 
women from low income and minority populations (Ickovics et al., 2007, Herrman et al., 2012, Novick et al., 2012, Picklesimer et al., 2012).

Implementing and providing this complex model, however, requires novel approaches and distinct resources. In clinical settings designed to provide individual care in examination rooms, these adaptations collectively represent a "paradigm shift" in prenatal care (Rising et al., 2004). These institutional adaptations often can be quite challenging. Difficulties reported include problems with scheduling, staffing, training, timely entry into care (Klima, 2009), and recruiting women into prenatal groups (Hackley et al., 2009, Teate et al., 2009, Tanner-Smith et al., 2012). In a program evaluation of five sites, four sites reported "implementation difficulties," including inadequate administrative buy-in and allocation of administrative time for managing Centering. Furthermore, this paradigm shift may be unsettling for clinicians and staff who view traditional, individual prenatal care as indispensible, or who are unfamiliar with the advantages of group health care (Strong, 2000, Novick, 2004, Yalom and Leszcz, 2005, Herrman et al., 2012, Tanner-Smith et al., 2012). Consequently, clinicians providing GPNC may confront resistance from colleagues, or encounter logistical challenges in implementing the Centering model as designed because of institutional limitations.

To date, there have been no studies published that examine directly and in depth the challenges faced by clinicians when providing group prenatal care. This study investigated some of these challenges. While collecting data for a qualitative parent study of women's experience of GPNC in two clinics, we were struck by the obstacles Centering group leaders encountered and by the discrepancy between program guidelines and program delivery. Although Centering is designed to accommodate variation, the extent and nature of the discrepancies raised questions about implementation and fidelity when translating Centering into clinical settings - problems that warranted further investigation. Consequently, we modified the study design, consistent with emergent design in qualitative research (Patton, 2002), to more fully explore the way Centering ${ }^{1}$ was actually being provided and the challenges encountered when delivering it.

The analysis was guided by these questions: 1) What do group leaders and participants identify as challenges related to the delivery of Centering? 2) How is the Centering model adapted to address contextual challenges in clinical settings? The findings reported illustrate the complexity of providing this promising model in settings designed for individual care.

\section{The CenteringPregnancy Model of Group Prenatal Care}

CenteringPregnancy provides prenatal care to groups of 8-12 women of similar gestational ages (Rising, 1998, Novick, 2004, Rising et al., 2004, Novick et al., 2011). After an initial individual prenatal visit for complete history and examination, women attend 8-10 two hour group sessions during pregnancy. In a typical session, women enter the group space without waiting, measure their own blood pressure, weigh themselves, and record findings in their health record. While awaiting physical examinations, they usually sit in chairs arranged in a circle, chatting together and completing self-assessment sheets, which are used later in discussions. Snacks are provided. Women are examined individually in the group space, often on a mat on the floor outside the group circle. After examinations, facilitated discussions cover pregnancy-related health topics and provide an opportunity for peer support. Women's partners and significant others often attend, although children are typically discouraged. Centering is ideally facilitated by two people, at least one of whom is

\footnotetext{
${ }^{1}$ For the remainder of this paper, the term "Centering" will be used rather than the term "GPNC," as both sites studied were using Centering materials.
} 
a prenatal provider. Sessions also can incorporate other perinatal professionals (e.g. social workers, nutritionists, pediatricians). A six-week postpartum reunion brings the group together to share birth experiences, to see one another's babies, and to establish continuing connections.

Centering has been demonstrated to improve important perinatal outcomes compared with individual prenatal care. In a randomized controlled trial (RCT) of 1047 women, Ickovics and colleagues (2007) demonstrated 33\% reduced risk of preterm birth, with a stronger effect in African-American women. Recently, a retrospective cohort study comparing 316 women who elected group prenatal care with women who elected individual care demonstrated a $47 \%$ reduction in preterm birth and reduced racial disparities in pregnancy outcomes for black women (Picklesimer et al., 2012). Women in the RTC also had higher rates of breastfeeding, although this was not demonstrated in an RCT in military settings (Kennedy et al., 2011) or in the retrospective cohort study. Women randomized to Centering were also less likely to be pregnant again at six months postpartum (Kershaw 2009), reported greater satisfaction with care, and were less likely to receive suboptimal care (Ickovics et al., 2007, Kennedy et al., 2011). Women who scored in the third tertile of stress on the Perceived Stress Scale who were randomized to Centering reported increased selfesteem, and decreased stress and social conflict (Ickovics et al., 2011). Qualitative studies report that women were enthusiastic about learning in groups, felt supported by other women and clinicians (Kennedy et al., 2009, Novick et al., 2011, Herrman et al., 2012, Novick et al., 2012), and found that talking with others normalized fears (Novick et al., 2011, Herrman et al., 2012).

The Centering Healthcare Institute (CHI) markets Centering resources and conducts model implementation and site approval processes. Site approval requires provision of 13 "Essential Elements of Centering" (Kennedy et al., 2009, Centering Healthcare Institute, 2011) (Table 1). Although over 300 sites have implemented Centering, there are only approximately 90 approved sites (Centering Healthcare Institute, 2011).

\section{Methods}

This analysis was part of a longitudinal, qualitative study of Centering in two urban clinics using interpretive description (Thorne, 2008). Parent study methods, reported in detail elsewhere (Novick et al., 2011), were modified to investigate issues surrounding provision and receipt of Centering. Data were elicited regarding barriers or facilitators group leaders encountered when providing Centering, divergence between how Centering was provided and CHI recommendations, and group leaders' reasons for modifying the model. We also incorporated data from a series that was discontinued after five sessions to gain insight into challenges of sustaining groups. During thematic analysis, we focused on data related to the contexts in which care was provided. Finally, to further explore contextual issues, we used Situational Analysis as an adjunct to traditional thematic analysis (described below).

\section{Setting and Sample}

The study was conducted at two Northeastern urban clinics serving primarily low income African-American or Hispanic women. Both sites used CHI materials, but, as the site approval process was only being developed, neither clinic was an approved site (Centering Healthcare Institute, 2011, Novick et al., 2011).

Women in both clinics were informed about Centering by their nurse-midwives during their initial obstetrical examinations, and offered the choice of receiving their care in the groups or individually. The sample was 49 participants attending five Centering series, clustered into five categories (See Table 2). The principal participants ( $n=23$ ), were pregnant women 
attending Centering groups who also participated in individual interviews. Nineteen principal participants were African American, three were Hispanic, and one was White; mean age was 22 years. Two certified nurse-midwife (CNM) group leaders (one per clinic) participated in individual interviews. The remaining participants $(n=24)$ were all others attending Centering sessions who consented to participant-observation. The mean number of pregnant women per session was 4.6 (range 1-8) over all the groups and sites.

\section{Data Collection}

Human subject committee approvals were obtained from Yale and both clinical sites. The first author obtained consent from subjects for interviews and participant-observation. Data were collected from March, 2007 through September, 2008. Data collection procedures were: 1) participant-observation of Centering sessions, 2) interviews with group leaders, 3) interviews with pregnant women, and 4) review of health records. For this analysis, principal data were participant-observation and group leader interviews, although women's interviews contributed women's perceptions of the impact of modifications on their experience of care.

Participant-observation-Participant-observation of 36 Centering sessions (4 completed and 1 incomplete series) described activities and interactions, and provided understanding of interview data in the context of these activities. Field notes recorded processes of care, interactions, differences between recommendations for providing Centering and actual implementation, and researcher impressions.

Individual interviews-Group leader interviews $(n=9)$ were conducted at the start and end of each series, and elicited the midwives' perspectives on women's experiences of Centering, factors in women's lives that influenced receiving Centering, barriers and facilitators encountered when providing Centering, and their own experiences of providing Centering. Pregnant women participated in a series of up to three interviews $(n=47)$ during pregnancy and the postpartum period, which included questions on their experience of Centering and on their personal lives, social contexts, and health care experiences in the clinic. Interviews were audiotaped and transcribed.

Health record review—Data from health records $(n=22)$ described the sample and enhanced our understanding of health and social circumstances that might affect pregnancy.

\section{Analysis}

Data analysis was inductive and began during data collection (Novick et al., 2011). ATLAS.ti qualitative software was used for data management. After coding, the first author identified key ideas and related codes, examined these codes for patterns, and then examined data within remaining codes. Next, codes specific to the situations in the clinics that affected receiving Centering were examined, and data were then compared across codes to identify initial themes. Themes were considered to be patterns that were prevalent, salient, and which revealed an understanding of the circumstances surrounding the provision of Centering. Integrating different data sources, profiles were developed of participants, Centering series, and sites. Using these profiles, we further developed initial themes.

After thematic analysis generated an initial understanding of the role contextual factors played in receiving and providing Centering, we employed a strategy, Situational Mapping, borrowed from Situational Analysis (Clarke, 2003, Clarke, 2005). Mapping helped us to identify additional factors influencing the provision of Centering, and to consider the impact of each factor on other elements in the situation. When no new ideas were generated from mapping, these ideas were integrated with preliminary themes, which were refined in 
collaboration with the second and fifth authors. This process yielded three clusters of findings related to the context in the clinics that affected how Centering was provided, which are presented below. Findings related to the contextual factors in the women's lives that affected how women received Centering are reported elsewhere (Novick et al., 2012)

\section{Findings}

The central finding of this research was that the clinics did not always provide full resources for implementing Centering as designed, resulting in multiple challenges for the group leaders. In response, the group leaders developed strategies for providing Centering within these limitations. Findings are presented in three sections: 1) Clinic Context describes the factors in the clinics surrounding and affecting providing Centering, 2) Group Leader Responses describes how group leaders responded to these circumstances, and 3) Downstream Effects depicts the consequences of clinic limitations and group leader responses. To maintain participant confidentiality, we intentionally have avoided creating clear portraits of individual women, group leaders, or sites.

\section{Clinic Context: Becoming an "Integral Part of the Clinic"}

Centering was a complex program to implement and maintain in clinics organized for individual prenatal care. The novel approach required significant commitment, or "buy-in," to this paradigm shift. Administrators had to embrace and promote Centering as a legitimate way to provide health care, and allocate resources to sustain the model. In this section, we describe factors in the clinics surrounding the provision of Centering, including buy-in and the effects of buy-in on resources and on how Centering was delivered.

Both institutions had Centering enthusiasts, but the group leaders also described "saboteurs" -individuals who were uncomfortable with the "disruption" created by Centering or who were unwilling to "think outside of the box." Some simply needed time to adjust to an unfamiliar approach. Although both clinics had this mixture of supporters and detractors, there were important differences in degree of buy-in. In the clinic with greater buy-in, there was substantial administrative support for implementing Centering; glitches were anticipated, and there was latitude to experiment. For example, an administrator unexpectedly offered additional funding for Centering supplies when she received a grant, and staff members sometimes served as ambassadors for Centering, generating further staff and patient interest. The midwife explained the gradual process of acceptance:

People are still getting used to this idea, and not just the clinical—the administrator folks. And everybody is like, "Oh, Centering. Oh, the group, right." It's becoming part of the norm at [clinic], so that's been fantastic.

In the other setting, there was minimal administrative commitment. The group leader felt that the program was being implemented at "glacier speed," and that staff did not view Centering as an "integral part of the clinic." Over time, however, several factors increased administrative support for Centering, including physician interest, recognition that Centering could free scarce examination space, and publication of research demonstrating improved outcomes with Centering.

In general, greater buy-in translated into better resources, including systems for recruiting and retaining Centering participants, allocation of group space, and staffing. Where buy-in was greater, several staff members actively recruited for Centering. In the other clinic, however, recruitment was "catch when catch can": newly pregnant women were simply handed a flyer for Centering and learned more only if clinicians elected to discuss Centering during individual visits. Retention systems were inadequate in both settings: when women required individual visits between sessions, they often were accidentally misdirected to 
return to individual care because, as one midwife explained, group appointment templates were "difficult for staff to comprehend," and there was no system to identify Centering participants. Neither clinic provided reminder calls.

The availability of physical resources also reflected degree of buy-in. CHI recommends group space that accommodates circular seating with room for floor exercises and demonstrations, areas to check blood pressure and weight, and space for conducting physical examinations privately (S.S. Rising, written communication, 2010). In the setting with greater buy-in, the large space was inviting and cheerfully decorated, with privacy for exams and storage. In the clinic with less support, however, Centering could only be scheduled when another department granted use of a small locked conference room without storage. Consequently, before every session, the group leader obtained keys, transported supplies, and rearranged furniture. She felt that dedicated group space would simplify logistics and legitimize Centering to the staff. (Eventually space was allocated which-although cramped and utilitarian-met fundamental group requirements.) The clinic with greater buy-in also provided more teaching materials. However, although both CNMs gave each woman binders with CHI educational materials, and used the binders during every session, no funds were allocated in either setting to buy additional binders. Finally, neither clinic provided snacks.

Buy-in also affected staffing. In addition to two co-facilitators for each session, Centering requires administrative time for session planning and follow-up. Consequently, clinicians should have 3.5-4 hours allocated per Centering session. To generate sufficient billable prenatal visits to balance staffing with productivity, groups should ideally enroll 10-12 women (S.S. Rising, written communication, 2009). Across groups and sites, however, attendance averaged 4.5 women per session, and Centering was not considered productive. Both clinics responded by staffing sessions with one midwife and no co-facilitator. Support for the midwife ranged from none to a staff person remaining throughout sessions. Both group leaders understood productivity concerns, noting that their clinics could not "afford" to "sacrifice" staff for Centering from regular clinic responsibilities with such low enrollment. Once again, in the clinic where buy-in was greater, the midwife had more consistent help and administrative time. The other midwife often conducted sessions alone, although this improved as buy-in increased. Furthermore, both clinics eliminated postpartum reunions, which are not billable.

\section{Group Leader Responses: "Just Deal With It"}

Although both clinics had taken many steps to provide Centering, limited resources generated challenges for the group leaders. Nevertheless, they were committed to providing Centering because they viewed it as "a great way of giving care" to their patients, who often had difficult lives. Many were impoverished, had demanding jobs or were unemployed, or had unstable living situations or difficult relationships with partners. Transportation or child care problems deterred clinic attendance, and once there, women often experienced long waits for brief individual visits. The midwives felt that Centering attenuated these problems: it utilized women's time well, provided social support, built ties within the community, and was fun (Novick et al., 2012).

The midwives, therefore, were pulled simultaneously in different directions by their sense of the high value of Centering, by limited resources, and by their views of how Centering should ideally be provided. One midwife captured this saying: "I' $m$ in a little bit of a hard spot here." Balancing commitment to Centering with pragmatism, the midwives developed two sets of strategies for realizing their long term goals within institutional constraints: advocating and compromising. 
Advocating - In both settings, Centering was vulnerable to being discontinued, or falling into what one midwife called "that dark hole." Although the CNMs were optimistic that Centering eventually would "fly," they were "pushing the envelope" to keep the model "alive." This included explaining the unfamiliar model to staff so that it would seem less "harebrained and off the wall," anticipating problems, and troubleshooting. They also advocated for staffing, supplies, systems for recruitment and scheduling, and space. Advocacy could mean simply articulating needs to responsive administrators. Sometimes it involved seizing the moment, such as when one midwife realized how to obtain space for groups:

For years apparently they [administrators] said, "No, we can't use that [room], because we're going to use it someday for this." Well, when "someday" comes, we'll work it out. But until then we're going to be, you know, running groups and doing good.

Alternatively, advocacy could entail incremental strategies and persistence. For example, one group leader wanted to enroll all pregnant women in Centering; those preferring individual care would "opt out." While other program elements were being solidified, however, she deferred pursing this goal. She explained: "After a while, once we get the rhythm, I'm going to be a-what do you call it?—a blister on their backsides, because I'm always going to be pushing to make it available for all women."

Compromising-The midwives believed that many of Centering's Essential Elements were indeed critical—but they lacked resources to provide them all. This created a dilemma: the group leaders could compromise and modify Centering, or not provide Centering at all. One midwife expressed her frustration saying, "We know what is needed to make it work well." The midwives—convinced of the value of Centering-compromised.

Compromising assumed several forms. One was improvisation: when unexpected problems arose, the midwives quickly analyzed situations, tried different approaches, or managed with any available resources. For example, one midwife learned immediately before a session that the group space was unavailable. Rather than cancel the session, her impromptu adjustments included locating another room and posting notes redirecting women. Because the substitute room lacked examination space, the midwife escorted women individually to the clinic where she negotiated examination space. One midwife explained why she sometimes chose to improvise, or go "by the seat of my pants": "It probably could change if I make a big deal about it, but I'm in a more 'just deal with it' frame of mind."

Other compromises were more sustained, such as assuming additional roles. For example, one midwife scheduled Centering sessions herself, the other midwife purchased group supplies with her own money, and both midwives sought outside funding. The most demanding role shifts, however, occurred during sessions and resulted from understaffing. In the clinic with greater buy-in, a staff member helped set up and assisted women to checkin. Once group discussion began, the staff member left, returning briefly at the session's close. The group leader preferred full support, but was willing to compromise: "We're working around it. I'm not one to say, 'I can't do this unless I've got X number of people.' I'd just as soon do a fair version of it and do it myself."

In the other clinic, however, no staff members were assigned to Centering, leaving the midwife to do two people's jobs simultaneously. Before sessions, she transported supplies, rearranged furniture, and cleaned the room. As women arrived, she alternated between assisting women with self-care and conducting examinations. She paused group discussions to greet late arrivals or give departing women appointments. After sessions, she moved supplies and furniture again. Although sometimes staff "volunteered" to help, she often 
managed alone. She viewed "schlepping and running back and forth to get stuff," as a necessary compromise.

Some compromises effectively modified the Centering model, and the group leaders tolerated some adaptations without endorsing them. For example, neither site provided snacks. Both group leaders felt the clinics should provide them, and one group leader simply purchased them herself. When administrators in both sites substituted examination tables for floor mats, both midwives initially resisted and then later compromised. One midwife tried using the table, but eventually reintroduced the mat. In the other site, however, the administration installed the table permanently. The group leader weighed her reluctance to ignore $\mathrm{CHI}$ recommendations against clinic constraints. She mused, "If it's done on a massage table within the group space, does it destroy the model?"

These modifications all had consequences, as we will discuss later. One final set of modifications, however, stood apart. The central idea of Centering is to bring together women with similar due dates in a way that encourages participation and mutual support.

These final modifications altered aspects of Centering that are fundamental to this idea, or at the heart of the model. These modifications were: 1) allowing children to attend, 2) extending enrollment over several sessions, generating a large range of gestational ages within groups, 3) terminating individual sessions or series early when attendance was low, and 4) allowing women to attend sessions for examinations without staying for group discussion.

These modifications were designed to increase attendance, to maintain productivity, and to accommodate women's difficult circumstances. One midwife described the factors in women's lives and the clinic that led her to end one series after five sessions:

We had that attrition, two delivered preterm, one transferred to high risk because she was diabetic. Another one got a job and the job wouldn't let her out. So when we went down to what, four people? And they were never coming at the same time, I said, "This is just not feasible, and I can't use the clinic time to do that." Because when people start looking at the numbers it's going to be very distressing.

For similar reasons, a group leader allowed women to come for examinations only. This generated a sense that people could casually drop in, rather than committing to spending two hours together. The group leader discussed her reasoning and feelings:

It's very annoying to me when people show up late or come and then have to leave, because I feel that they're not really participating in group. But with several of those women, it was issues relative to their children and ride availability. It was a loss for them and for us as a group to not have them as involved. I continued to have them come to group whereas I probably would have said "Looks like this is not going to work for you, you need to go back to individual care." But I did that because to lose them as a number in the group meant that I would have to close the group and move everybody to individual care. And so my tolerance for that was probably greater. Because I wanted to continue to do the groups because my sense was that if we lost momentum, then groups would never happen.

However, the other group leader felt it was important for women to remain through group discussions to promote group cohesion. She conveyed this expectation to her groups and this rule was generally observed.

\section{Downstream Effects: Feeling "Helter-skelter"}

Collectively, limited resources and program modifications had consequences. They affected the midwives' ability to provide care, women's experiences of receiving Centering, group 
cohesion, program stability, and the midwives' experiences of providing Centering. In this section, we discuss these downstream effects.

A unique feature of Centering is having a clinician conduct examinations within the group space. However, when support staff was not available to greet women and facilitate group activities, group leaders conducted examinations while managing the entire group.

Sometimes these demands conflicted, threatening to compromise care. For example, when one woman's blood pressure was seriously elevated, the midwife immediately took her to the clinic, leaving other group members waiting. The midwife commented that proper planning could avoid these predictable disruptions: "Things will happen with any of the pregnant women at any given point. You can't rely on having to call out to get somebody to come in and help, "cause it makes the flow very disjointed." The other midwife worried that insufficient administrative time for chart review and follow up also compromised care.

Suboptimal resources and model modifications may have also affected women's experiences. One group leader was concerned that being "distracted doing all this other stuff" decreased the amount or quality of time she spent with the women. Although women's experiences were predominantly very positive (Novick et al., 2011), participants noted problems. One woman suggested: "Maybe having another midwife would have helped, because there were a good-sized group of pregnant women." Participants who attended a busy first session with no support staff commented that things could have been "better organized," with activities while waiting for examinations. Women commented that food, when present, attenuated the awkwardness of waiting; when absent, women suggested providing snacks. Women also expressed disappointment that postpartum reunions were not held, as they had been eager to see each others' babies. Allowing children to attend groups also may have affected women's experience. Women were particularly concerned about the disruption their own children might cause (Novick et al., 2011). One midwife explained:

It's a very stressful time for the parents because they want their kids to behave, and if they don't, it's very obvious, everybody's looking and there's, like, judgments. We're not seeing optimal parenting; and when we're talking about parenting, it makes it doubly awkward because we all know who we're talking about for bad parenting. So I think that is kind of unfair to the moms there. But I'm always willing to give it a try.

However, sometimes clinic constraints became opportunities. One midwife noted: "The women really bonded. They'd come in, and they'd help me set up. And they were very eager to engage." Children attending groups provided opportunities to address parenting, as this group leader described:

"When you put it into context, like, "Well, it is normal. I think they are doing very well for this age to be sitting this long," it's sort of modeling what is reasonable behavior for a child versus what may be not so good."

Clinic constraints and modifications also may have affected group stability. Permitting enrollment over several months resulted in sparse attendance at early sessions and toward the end, as women gave birth. Extended enrollment also meant that gestational ages spanned several months; thus women were not all scheduled to return together. Women did not realize this, however, and sometimes commented that they had not gotten to know certain women, or that they were poor attendees. Thus, extending enrollment may have affected women's relationships, participation, learning, investment, and group cohesion. Allowing women to drop in for examinations may have had similar effects. Furthermore, difficulty in scheduling new series undermined momentum, putting Centering at risk of being discontinued or going "off the screen" in both clinics. 
Finally, juggling multiple competing roles during sessions without assistance sometimes left the midwives feeling beleaguered. One midwife commented, "Sometimes I felt, like, helterskelter trying to do everything ... doing this by myself, it's more work than one-on-one care." At times, the stresses diminished the midwives' enthusiasm for Centering. After a particularly challenging session, one midwife said, "The joy of doing groups is gone." The other midwife eventually decided to "take a break" from running groups. In one clinic, however, positive changes were eventually instituted, freeing the midwife to focus on providing safe care and facilitating groups.

\section{Discussion}

CenteringPregnancy is being implemented increasingly widely across the U.S and internationally. Our analysis discovered that this innovative model-which requires a different institutional infrastructure and mindset for clinicians and administrators accustomed to individual care — can be difficult to provide and sustain. In the clinics studied, institutional constraints had profound effects on how Centering was implemented, and created multiple challenges for the CNMs facilitating groups. These findings thus reveal critical issues facing individuals and institutions implementing Centering.

Although both clinics took many steps to provide Centering, administrators and staff did not always embrace the non-traditional approach and the clinics did not provide resources for fully implementing and sustaining Centering. Principal shortcomings were inadequate administrative systems, group space, and staff support. Despite these challenges, the group leaders were deeply motivated to persevere because they viewed Centering as an effective way to care for women with difficult lives. Consequently, they served as advocates for Centering and they compromised by improvising and by assuming additional roles. The most critical compromises, however, entailed modifying the Centering model—by adapting delivery to accommodate clinic limitations, or by developing modifications to address perceived problems.

Certain modifications may have offered benefits. When allowed to drop-in for examinations only, women came at their convenience, chatted informally as if attending a community drop-in center, and received physical care. Those who stayed longer received extensive educational content and peer support. This arrangement might not confer Centering's full benefits; nevertheless, the value of receiving care in a comfortable setting might have outweighed the disruptive effects of irregular attendance. Allowing children in groups provided both benefits and disadvantages for women. Children can be disruptive to their parents and to other participants and they cannot reasonably be expected to maintain confidentiality. The presence of children in groups may inhibit discussion of mature topics such as sexuality, intimate partner violence, or substance abuse, or, alternatively, children may be exposed to issues that might not be age-appropriate. On the other hand, in the observed groups, children often served as conversational icebreakers, contributed to the informal social atmosphere, and provided opportunities to discuss childrearing issues (Novick et al., 2012).

Other modifications clearly had adverse consequences. Inadequate systems for recruitment and retention contributed to low enrollment in Centering: mean attendance was 4.6 women, and some sessions had only one or two participants, which is not really a group. Low enrollment generated concerns about productivity and, to increase billable visits, midwives permitted women to enroll over several sessions and to attend for examinations only. Paradoxically, however, these modifications may have resulted in decreased participant investment in groups and reduced sense of group cohesiveness and mutual engagement. This may have further contributed to a downward spiral of lower attendance and investment in 
groups and the destabilization of the clinics' Centering programs (Novick et al., 2011). Examples of these effects include the discontinuation of one series after five sessions due to low enrollment, and the fact that Centering was discontinued in one of the clinics. Finally, although the midwives had initially loved facilitating groups and were willing to serve as advocates for Centering, they often felt frustrated and harried. Discouragement induced one group leader to consider discontinuing providing Centering, and the other actually did so. Collectively, these findings suggest that some modifications might have had unfavorable consequences; indeed, in some cases, the effects were precisely the opposite of what had been intended. Furthermore, a committed advocate, or "champion" (Greenhalgh et al., 2004), may not be sufficient when organizational support is limited.

These findings are echoed in the broader literature about implementation of programs that redesign care to address social factors that affect health. Such programs often intentionally target vulnerable populations such as low income and/or minority groups, yet the agencies serving them may have limited resources and may be unable to mount the investment required to fully provide such complex programs (Berwick, 2003, Glasgow and Emmons, 2007). Consequently, financial concerns may generate "perverse incentives" which interfere with proper implementation (Glasgow and Emmons, 2007). These findings also raise questions about model fidelity vs. adaptation. Centering is designed to be adapted to different populations and settings, while maintaining the Essential Elements. However, some modifications were made in response to constraints, rather than to enhance care, and not all elements were preserved. It is not known however, which elements or combinations of elements are responsible for improved outcomes, and there are no published data on whether modifying these elements adversely affects outcomes-regardless of motivation.

Furthermore, most modifications observed in this study were responses to productivity concerns, but there are no published studies reporting on Centering's financial impact on institutions (Mooney et al., 2008) or the effect of modifying Centering on efficiency or costeffectiveness.

\section{Implications}

The findings from this study suggest that caution should be exercised when making decisions about adapting Centering, and that strategies are needed to enhance the success and sustainability of Centering. One suggestion for properly translating complex interventions is to implement them incrementally (Glasgow and Emmons, 2007). The sites in this study indeed utilized such an approach at times, but there is no evidence that Centering is effective or sustainable when implemented gradually. Another proposed strategy for maintaining innovative programs is to include staff training and ongoing systems for solving new problems (Neumann et al., 2010). CHI has a developed a "Model Implementation Plan" (MIP) which includes readiness assessment, system redesign, developing administrator support, staff training, and ongoing consultation. However, MIP cost ranges from $\$ 15,000-\$ 45,000$ (Centering Healthcare Institute, 2011), which may be prohibitive for low-resource organizations. If this approach proves successful, funding strategies will be needed to enable low-resource agencies to utilize the MIP.

This study, while revealing many previously unexamined problems, is an initial step in studying the translation of Centering into varied "real-world" settings. Further research is needed to identify barriers and facilitators to implementing and sustaining Centering on several levels: within health systems, within the Centering model and MIP, and in the policy arena. We also need to identify "active ingredients" of Centering and to better understand the impact of modifying Centering on outcomes, efficiency, cost-effectiveness, women's experience of care, clinicians and settings, and long-term sustainability. Furthermore, because sites and clinicians may modify Centering either in response to challenges they confront in implementing Centering or for a variety of other reasons (Wedin et al., 2010, 
Andersson et al., 2011, Gaudion et al., 2011), some versions of group prenatal care may not meet the criteria for being considered "Centering." However, these non-Centering versions of group prenatal care may still improve outcomes over individual care, and studying these versions may help us understand which elements of group prenatal care truly improve outcomes. We therefore need to develop approaches for conducting research on both CHIapproved Centering sites and on other versions of group prenatal care. Ultimately, this knowledge will generate strategies for translating the important health benefits of Centering, which have been demonstrated under controlled circumstances, to be conferred upon women receiving Centering as part of their routine prenatal care in varied clinical settings.

\section{REFERENCES}

Andersson, E.; Christensson, K.; Hildingsson, I. Parents' experiences and perceptions of group-based antenatal care in four clinics in Sweden. Midwifery. 2011. epub Sept 17, 2011. http:// www.sciencedirect.com/science/article/pii/S0266613811001008

Berwick DM. Disseminating innovations in health care. JAMA : The Journal of the American Medical Association. 2003; 289(15):1969-1975. [PubMed: 12697800]

Centering Healthcare Institute. Centering care start up. Centering Healthcare Institute; 2011.

Centering Healthcare Institute. Locate a Centering Site. 2011.

Centering Healthcare Institute. Site approval: Centering Healthcare site approval process. 2011.

Clarke AE. Situational analyses: Grounded theory mapping after the postmodern turn. Symbolic Interaction. 2003; 26(4):553-576.

Clarke, AE. Situational analysis: Grounded theory after the postmodern turn. Thousand Oaks, CA: Sage; 2005.

Gaudion A, Bick D, Menka Y, Demilew J, Walton C, Yiannouzis K, Robbins J, Rising SS. Adapting the CenteringPregnancy model for a UK feasibility study. British Journal of Midwifery. 2011; 19(7):433-438.

Gaudion A, Menka Y, Demiter J, Walton C, Yiannouzis K, Robbins J, Rising SS, Bick D. Findings from a UK feasibility study of the CenteringPregnancy model. British Journal of Midwifery. 2011; 19(12):796-802.

Glasgow RE, Emmons KM. How can we increase translation of research into practice? Types of evidence needed. Annual Review of Public Health. 2007; 28(1):413-433.

Greenhalgh T, Robert G, Macfarlane F, Bate P, Kyriakidou O. Diffusion of innovations in service organizations: Systematic review and recommendations. Milbank Quarterly. 2004; 82(4)

Hackley B, Applebaum J, Wilcox W, Arevalo S. Impact of two scheduling systems on early enrollment in a group prenatal care program. Journal of Midwifery \& Women's Health. 2009; 54(3):168-175.

Herrman JW, Rogers S, Ehrenthal DB. Women's perceptions of CenteringPregnancy: A focus group study. MCN: The American Journal of Maternal/Child Nursing. 2012; 37(1):19-26.

Ickovics J, Reed E, Magriples U, Westdahl C, Rising S, Kershaw T. Effects of group prenatal care on psychosocial risk in pregnancy: Results from a randomised controlled trial. Psychology and Health. 2011; 26(2):235-250. [PubMed: 21318932]

Ickovics JR, Kershaw TS, Westdahl C, Magriples U, Massey Z, Reynolds H, Rising SS. Group prenatal care and perinatal outcomes: A randomized controlled trial. Obstetrics \& Gynecology. 2007; 110(No. 2, Part 1):330-339. [PubMed: 17666608]

Kennedy HP, Farrell T, Paden R, Hill MS, Jolivet R, Cooper BA, Rising SS. A randomized clinical trial of group prenatal care in two military settings. Military Medicine. 2011; 176(10):1169-1177. [PubMed: 22128654]

Kennedy HP, Farrell T, Paden R, Hill S, Jolivet R, Willetts J, Rising SS. "I wasn't alone" -- A study of group prenatal care in the military. Journal of Midwifery \& Women's Health. 2009; 54(3):176183.

Klima C. Introduction of CenteringPregnancy in a public health clinic. Journal of Midwifery and Women's Health. 2009; 54(1):27-34. 
Lu MC, Kotelchuck M, Hogan VK, Johnson K, Reyes C. Innovative strategies to reduce disparities in the quality of prenatal care in underresourced settings. Medical Care Research and Review. 2010; 67(5):198S-230S. [PubMed: 20675351]

Mooney SE, Russell MA, Prairie B, Savage C, Weeks WB. Group prenatal care: An analysis of cost. Journal of Health Care Finance. 2008; 34(4):31-41. [PubMed: 21110479]

Neumann MS, O'Donnell L, Doval AS, Schillinger J, Blank S, Ortiz-Rios E, Garcia T, O'Donnell C, R. Effectiveness of the VOICES/VOCES sexually transmitted disease/Human Immunodeficiency Virus prevention intervention when administered by health department staff: Does it work in the "real world"? Sexually Transmitted Diseases. 2010

Novick G. CenteringPregnancy and the current state of prenatal care. Journal of Midwifery \& Women's Health. 2004; 49(5):405-411.

Novick G, Sadler LS, Kennedy HP, Cohen SS, Groce NE, Knafl KA. Women's experience of group prenatal care. Qualitative Health Research. 2011; 21(1):97-116. [PubMed: 20693516]

Novick G, Sadler LS, Knafl KA, Groce NE. The intersection of everyday life and group prenatal care for women in two urban clinics. Journal of Health Care for the Poor and Underserved. 2012; 23(12):589-603. [PubMed: 22643609]

Patton, MQ. Qualitative research \& evaluation methods. Thousand Oaks, CA: Sage; 2002.

Picklesimer AH, Billings D, Hale N, Blackhurst D, Convington-Kolb S. The effect of CenteringPregnancy group prenatal care on preterm birth in a low-income population. Am J Obstet Gynecol. 2012; 206(5):415.e411-415.e417. [PubMed: 22542115]

Rising SS. Centering Pregnancy: An interdisciplinary model of empowerment. Journal of NurseMidwifery. 1998; 43:46-54. [PubMed: 9489291]

Rising SS, Kennedy HP, Klima CS. Redesigning prenatal care through CenteringPregnancy. Journal of Midwifery \& Women's Health. 2004; 49(5):398-404.

Strong, TH. Expecting trouble: What expectant parents should know about prenatal care in America. New York, NY: New York University Press; 2000.

Tanner-Smith, EE.; Steinka-Fry, KT.; Lipsey, MW. A multi-site evaluatiojn of the CenteringPregnancy Programs in Tennessee. Nashville, TN: Vanderbilt University; 2012.

Teate A, Leap N, Rising SS, Homer CS. Women's experiences of group antenatal care in Australia-the CenteringPregnancy Pilot Study. Midwifery. 2009

Thorne, S. Interpretive description. Walnut Creek, CA: Left Coast Press; 2008.

Wedin K, Molin J, Crang Svalenius EL. Group antenatal care: new pedagogic method for antenatal care--a pilot study. Midwifery. 2010; 26(4):389-393. [PubMed: 19108938]

Yalom, ID.; Leszcz, M. The theory and practice of group psychology. New York, NY: Basic Books; 2005. 
Table 1

\section{ESSENTIAL ELEMENTS OF CENTERINGPREGNANCY $a$}

1 Health assessment occurs within the group space

2 Participants are involved in self care activities

3 A facilitative leadership style is used

4 Each session has an overall plan

5 Attention is given to the general content outline; emphasis may vary

6 There is stability of group leadership

7 Group conduct honors the contribution of each member

8 The group is conducted in a circle

9 Opportunity for socializing is provided

10 The composition of the group is stable but not rigid

11 Group size is optimal to promote the process

12 Involvement of family and support people is optional

13 There is outcome evaluation

$a_{\text {http://www.centeringhealthcare.org/pages/media/elements_powerpoint.php }}$ 
Table 2

Study Participants and Data Sources

\begin{tabular}{|l|l|l|}
\hline Type of Participant & Role in group & $\begin{array}{l}\text { Study participation and number of } \\
\text { interviews conducted }\end{array}$ \\
\hline $\begin{array}{l}\text { Principal Participants } \\
(\boldsymbol{n}=\mathbf{2 3})\end{array}$ & Pregnant women & $\begin{array}{l}\text { Interviews }(n=47) \\
\text { Participant-observation } \\
\text { Medical record review }(n=22)^{*}\end{array}$ \\
\hline $\begin{array}{l}\text { Pregnant women } \\
(\boldsymbol{n}=\mathbf{1 2})\end{array}$ & Pregnant women & Participant-observation only \\
\hline Guests $(\boldsymbol{n}=\mathbf{9})$ & Partners, family of & Participant-observation only \\
\hline Staff $(\boldsymbol{n}=\mathbf{3})$ & Support staff & Participant-observation only \\
\hline Nurse-midwives $(\boldsymbol{n}=\mathbf{2})$ & Facilitated groups & $\begin{array}{l}\text { Interviews }(n=9) \\
\text { Participant-observation }\end{array}$ \\
\hline
\end{tabular}

* One principal participant declined record review 